\title{
INTERRUPTED CASE STUDIES IN MATERIALS ENGINEERING
}

\author{
Marta Cerruti \\ Materials Engineering, McGill University, 3610 University Ave Montreal, QC \\ marta.cerruti@mcgill.ca
}

\begin{abstract}
The interrupted case studies method uses case studies taken from real-world problems, and breaks them down in smaller pieces; the students work on the smaller parts in teams during the lecture, and get feedback from the professor before moving on to the next part of the case. I used this approach in a Materials Engineering class taken by undergraduate students in their second year, titled "Analytical and Characterization Techniques". The method engaged the students very effectively during class time and seemed to promote deeper learning of key concepts. The method seemed to be particularly effective with students with learning disabilities.
\end{abstract}

Keywords: active learning, case studies, student engagement, participatory learning, in-class discussions, group work.

\section{INTRODUCTION}

Traditional lectures start with the professor teaching a concept that students don't know anything about. The professor implicitly asks the students to trust her; usually they will understand later in the course why the material taught is important.

An alternative approach would be to simulate natural learning. Children learn because they face a problem and they are interested in solving it. They learn during the process of trying to solve it, and that deep learning experience stays with them for the rest of their life.

To simulate such learning experience, I ran a pilot project of "interrupted case studies" in a 300-level Materials Engineering course titled "Analytical and Characterization Techniques" (MIME 317). The interrupted case studies method uses case studies taken from real-world problems, and breaks them down in smaller pieces; the students work on the smaller parts in teams during the lecture, and get feedback from the professor before moving on to the next part of the case [1]. This approach has been used in natural sciences [2] but this was the first attempt in an Engineering setup.

In MIME 317 students are exposed to many different techniques, from basic metallurgical analysis to advanced characterization. It is taught by myself and three other professors, which makes it even harder for students to see connections between all parts. While this is a difficult class, being able to characterize different materials is one of the qualifying skills of a materials engineer.

With the help of one of the co-teachers, we were able to introduce interrupted case studies for approximately $60 \%$ of the course. A trained graduate student helped developing all case studies, which were mostly simplified versions of research articles on topics ranging from star compositions to food adulteration. A final case study on art restoration challenged the students with different techniques together.

\section{METHODS}

\subsection{Case study development}

The case studies were developed based on examples provided by Prof. Revati Masilamani at a SALTISE conference. The examples brought by Prof. Masilamani were tailored for natural scientists/biologists [2]. For MIME 317, we developed cases studies tailored to Materials Engineers. They were developed mostly based on research articles that applied the techniques introduced in class to subjects that the students could relate to (e.g., food poisoning). In one case, the case study was prepared based on different sources that were not research articles.

The case studies assumed very little prior knowledge on the concepts described, and related to the techniques developed in class (Metallography, UV-vis spectroscopy, Absorption and Emission spectroscopy, IR spectroscopy). We also developed an introductory case study on a technique that was not related to the course, to get the students to understand the method, and a final case study on art restoration that pooled together different techniques learned during the class (discussed with case studies or not), and a few new ones.

All case studies were developed in collaboration with Vivienne Tam, a graduate student hired for this job.

\subsection{Case study deployment}

Students had access to the case study pertaining to the lecture online, before the lecture started (except for the introductory case study, which was handed in in class).

At the beginning of each case study lecture, the students would sit down in pre-determined groups. The same groups 
were kept through the semester. Then, the instructor would start the description of the case study, very briefly. Usually the students would be shown a graph, and would be given very few instructions on what the graph was about. They would have then three-four questions to discuss with their group mates. The questions would ask them to try to understand different aspects of the figure shown, based on previous knowledge from other courses, and their intuition. The discussion would last approximately 10 minutes.

During this time, the instructor and the graduate student co-developer would go around the classroom, and listen to the students' discussions. They would occasionally intervene if they saw that the students were stuck on wrong concepts, or if explicitly asked a question. But most of the times they were simply observers of the students' interactions.

After this time, the instructor would stop the discussion and ask different groups to share their answers with the rest of the class. The instructor and the class would have an indepth discussion of the concepts introduced, so that after that the students grasped the most important concepts introduced in this first part.

The second part of the case study would then be introduced-another figure to discuss, or table. The students would then answer the questions related to this part, again in groups, for another 10 minutes. Then the discussion would be brought back to the class altogether, again.

Usually this process would be repeated three times. At the end of these three "interrupted" sections, the class reached an intuitive, but rather deep, understanding of the main concepts related to the characterization technique. After this, the standard frontal lecture would start, and the instructor would discuss her material with the student using her preferred teaching methods. The instructor would usually continue for one to three lectures teaching material related to that technique.

The case study had a fourth section, which was left with the students. This fourth section broadened the horizon of the discussion, for example by asking the students to design an experiment with the technique learned. The students were supposed to think about these questions at home. On the day of the final lecture dedicated to the specific technique, the instructor would start the lecture as a case study lecture (ie with students sitting in groups), and ask the students to share their thoughts on the questions related to the fourth section in their groups. After this, the instructor would then ask the groups to share altogether with the class and comment on them so that the students could understand the correct concepts.

\subsection{Final case study}

The final case study on art restoration was a take-home assignment, and one full lecture was dedicated to its discussion. The groups were divided so that half of them would think about one third of the case study, another half to another third, and the last third would be discussed in class altogether, after hearing the answers from all groups.

\subsection{Case study evaluation}

The case studies were evaluated based on attendance and participation. Each case study counted for $2 \%$ of the grade, for a total of $10 \%$ of the grade based on case study. Also, I had a section of my final structure as 'mini-case studies', and I told the students in advance about it.

\section{RESULTS AND DISCUSSION}

Class participation during case studies was excellent. The students were actively discussing during each of the phases, and their discussions were extremely interesting and deep, exceeding my initial expectations. The instructor that agreed to participate in this case study trial was so enthused that she came to my office stating that now she wanted to do case studies in all of her courses!

Our observation was that almost all the students were very actively engaged. Only 1 student out of 43 clearly did not participate in any of the discussions (kept playing with his phone).

An unexpected outcome was that the method seemed to favor students with learning disabilities. My hypothesis on this is that the method asks students to make connections and does not require any memorization, so that students with learning disabilities such as ADHD have no disadvantages over other students, and may be in fact helped by their condition due to the high level of brainstorming and intuition required in case study discussions.

On my side, I noticed that the students were following my explanations a lot better for the techniques that I introduced via the case study method. I did not have to cut any material compared to previous years, because the students had understood the important concepts so deeply during the case study discussion that I was able to go much faster during the traditional part of the explanations. Also, a lot of the examples I used to introduce became redundant because of the ones already provided during the case study.

Students were very happy with the method. An exit survey taken by all students (43) showed that for the great majority the interrupted case studies approach was very $(50 \%)$ or extremely $(20 \%)$ effective to learn the course material; and for almost all of them it was very $(35 \%)$ or extremely $(63 \%)$ effective to understand real world application of the course.

The written comments left by the students highlighted that they particularly appreciated that the case studies provided real examples, thus allowing them to better understand the theory; they liked sharing their opinions with peers, which allowed them to think about things they 
did not initially consider by themselves; they found that the case studies challenged them and allowed them to learn more actively, which brought them to remember the concepts better than usual.

All $(100 \%)$ students who volunteered to take a follow up survey (22) said that they would recommend using the interrupted case study approach MIME 317 in the future.

In my section on the final, most students did better on the two mini-case studies than on the rest of the questions, and performing well on the "mini-case studies" problems in the final was a better predictor of student performance on my section than other questions I proposed; however, performing better on my section overall was a better overall course performance predictor than the mini-case study section only. Overall grades (on my section, or on the overall class) did not significantly improve compared to previous years.

\section{CONCLUSIONS}

The interrupted case studies created a very engaging environment for student learning and received very positive feedback from both students and instructors involved. The method, initially proposed for natural science students, can be easily adapted to an engineering course. I highly recommend this method for all classes introducing difficult and diverse concepts, as a way to promote deeper and more active learning. Different evaluation methods should be introduced to understand the effectiveness of the methods in the long term, especially if the method was used in several courses throughout the curriculum.

\section{REFERENCES}

[1] Herreid CF. The interrupted case study method. J College Sci Teaching, 2005;35(2):4-5

[2] White TK, Whitaker P, Gonya T, et al. The use of interrupted case studies to enhance critical thinking skills in biology. $J$ Microbiol Biol Educ. 2009;10(1):25-31. Published 2009 Dec 17. 